DOI: https://doi.org/10.46991/AFA/2021.17.2.053

\title{
SARCASM AS A BREACH OF LINGUISTIC POLITENESS: SOME THEORETICAL ASSUMPTIONS
}

\author{
Hayk Danielyan* \\ Yerevan State University
}

\begin{abstract}
The current paper is devoted to the analysis of sarcasm as a breach of principles of politeness. The aim of the paper is to elicit the peculiarities of sarcasm as an exception to the Politeness Principle suggested by G. Leech (2014) and its conversational function incorporated into the Irony Principle as mock politeness. The Politeness Principle demonstrates that sarcasm is apparently its exploitation as in the case of sarcastic utterances the illocutionary goal opposes the social goal thus providing breach in the model of politeness. The Irony Principle illustrates an explanation of polite utterances appearing as impolite arguing that polite interpretations of such utterances are unsustainable. To support the theory certain examples are analyzed retrieved from an American Depression-era author John Dos Passos's novel "1919". As a matter of fact, the debate is around the question whether sarcasm is an apparent exploitation of polite implicature of utterances or it is a category of impoliteness appearing as mock politeness.
\end{abstract}

Keywords: sarcasm, conversational irony, politeness, Politeness Principle, Irony Principle, impoliteness.

\section{Introduction}

Sarcasm or conversational irony as referred to by many theorists (Leech, 2014; Gibbs \& Colston, 2007) is an apparent exception to the Politeness Principle (PP) at the same time actually being an exploitation of it. Leech (2014) argues that the "Irony strategy" is a second-order strategy rooted in violations of the Politeness Principle which is analogous to Grice's (1975) Cooperative Principle (p. 100). In order to grasp a complete understanding of the abovementioned argument we need to elicit the pragmatic conception of the Politeness Principle and find out its relations to sarcasm as a breach of linguistic politeness which is the main concern of the current research. Conversational irony is a term that is preferred by different theorists over

\footnotetext{
*hayk.danielyan3@ysumail.am
}

Received: $\quad 30.04 .2021$

Revised: $\quad 28.06 .2021$

Accepted: 15.09 .2021

This work is licensed under a Creative Commons Attribution-NonCommercial 4.0 International License.

(C) The Author(s) 2021 
sarcasm to limit the denotation of the term irony. Irony is apparently referred to as a non-verbal phenomenon. In literary studies irony is classified in the group of rhetorical devices or figures of speech. The Irony Principle suggests that the conversational function of irony exposes its infelicity conditions by impolite behavior implicating that polite interpretations of impolite utterances are unsustainable. Ironic interpretations of the utterances may be considered as breaches of Quality and Quantity maxims in the sense that they indicate overstatement and understatement of truth.

The object of the current research is the study of sarcasm from a pragmalinguistic point of view to discover its relations with politeness principles. The research is inclined to review the Irony Strategy to provide some explanations of sarcasm as a category of impoliteness. For this purpose, descriptive and contextual methods of analysis are applied in the present study. The novelty of the research is determined by the fact that sarcasm is viewed as a breach of politeness principles as it is debatable whether sarcasm is a category of politeness conveying impolite implicature as an overstatement of truth, or a category of linguistic impoliteness as an understatement or attitude clash.

\section{The politeness principle}

The model or theory of politeness was first proposed to be adopted by Leech in 1983 and then restated in 2014. Leech's model is strongly contradicted by Brown and Levinson's seminal exposition of politeness (1987). The most highlighted contradiction lies under the definitions of positive and negative faces as pragmatic categories. Brown and Levinson's definitions are as follows:

Positive face: the positive consistent self-image or personality (crucially including the desire that this self-image be appreciated and approved of) claimed by interactants.

Negative face: the basic claim to territories, personal preserves, rights to non-distraction - i.e. to freedom of action and freedom from imposition (Brown, \& Levinson, 1978, p. 61).

These definitions are considered to be universalist claims of Western societies and are rejected by Eastern critique (Gu, 1990; Mao, 1994; Ide, 1993; Matsumoto, 1988; Wierzbicka, 1991/2003). Commonly referred to as "universal maxims" these claims never got accepted by the majority of theorists and were criticized. Leech argues the idea of "universal principles" and states that a model of politeness should be generalizable to various cultures and provide the basis for studying (im)-politeness in different languages and 
societies (Leech, 2014, p. 83). The conception of politeness between societies may vary yet without being greatly separated. Polite communication assumes that the speaker is taking into consideration both individual and group values. It is generally assumed that in Eastern societies group values are stronger, whereas in Western societies individual values are of greater relevance.

Despite all the criticism, Leech's restatement of the treatment of the principles of politeness is the basic model to comprehend the notion of politeness as a pragmatic phenomenon. According to the theory, politeness is a restriction examined in human communicative behavior, affecting the speakers to avoid communicative offense or discord, and increase communicative comity or concord. Politeness is an aspect of goal-oriented behavior. To say that the speaker is being polite in using a specific utterance is to say that the speaker's goal in using that utterance is to convey an impression of politeness towards other people. However, politeness is concerned with avoiding discord and fostering concord, only insofar as these are manifested through communication, especially through what meanings are expressed or implicated (Leech, 2014, p. 87-88). To project this conception to the idea of sarcasm or conversational irony as a mock politeness we need to take into account the two kinds of politeness scale. The two ways of looking at politeness are as follows:

Pragmalinguistic politeness scale: We can order utterances on a scale of politeness while keeping context invariant. For example, out of context, on the pragmalinguistic scale of politeness, we can judge that Can I borrow your camera? is more polite, as a request, than Lend me your camera, and is less polite than Could I possibly borrow your camera?

Sociopragmatic politeness scale: This is politeness relative to norms in a given society, group, or situation. Unlike the absolute or semantic scale, it is sensitive to context and is a bidirectional scale. Hence it is possible that a form considered more polite on the pragmalinguistic politeness scale is judged less polite relative to the norms for the situation. For example, Could I possibly interrupt? could be understood as "too polite," say, if spoken to family members monopolizing the conversation; it would probably be interpreted as sarcastic and hence offensive (Leech, 2014, p. 88).

Thus, the model of politeness stretches the first reference to sarcasm as an offensive utterance interpreted in sociopragmatic politeness scale. This means that the goal-oriented behavior of the speaker to appear polite may be breached if the utterance could be understood as "too polite" in an unexpected context, 
hence providing the implication of the speaker to mean the opposite of what is uttered, i.e. appearing sarcastic.

According to Leech (1983), there are certain maxims (Tact and Modesty) to represent the goals speakers pursue to maintain communicative concord. This assumes that there are some illocutionary goals that we want to achieve in our linguistic communication. But besides this, there are also certain social goals of communication, like to maintain strong communicative relations, and illocutionary goals may sometimes match or oppose the social goals. If we want to maintain good relations, we say something polite. In this case the illocutionary goals match the social goals. But if we make a request or criticize, the illocutionary goal opposes the social goal. Now, in the case of sarcastic utterances the illocutionary goal opposes the social goal, thus providing breach in the model of politeness and can be viewed as negative politeness. This kind of politeness may involve a negative purpose and intend to avoid a direct offense or verbal aggression. And the reason to use this kind of politeness is to mitigate the degree to which the speaker's goals are imposed on the hearer.

The further study of politeness principles shows that the concept of politeness should not be oversimplified, as in practice, politeness is a matter of degree and can be conditioned by different factors. Here, it is important to mention the pragmatic category of horizontal distance like the communication between familiar interlocutors. When the horizontal distance is reduced, the need for politeness is also reduced, hence like Grice's Cooperative Principle, the Politeness Principle can be violated, exploited or suspended (Leech, 2014, p. 99), and sarcasm or conversational irony is ascribed to be one of those exploitations conveying more of an impolite communicative behavior.

As mentioned in the introductory part of the research, sarcasm is an apparent exploitation of the Politeness Principle and is referred to as mock politeness. Culpeper treats sarcasm as a category of impoliteness. According to him sarcasm or mock politeness is performed with the use of politeness strategies that are obviously insincere, and thus remain surface realizations. Sarcasm is mock politeness for social disharmony and is clearly the opposite of banter which is mock impoliteness for social harmony (Culpeper, 1996, p. 356357). Thus, sarcasm is contrasted to banter, as being a category of impoliteness, it actually mocks by polite behavior, whereas banter mocks by impolite behavior. Leech states that if you must cause offence, at least do so in a way which doesn't overtly conflict with the Politeness Principle, but allows the hearer to arrive at the offensive point of your remark indirectly, by way of an 
implicature (Leech, 1983, p. 82). He believes that this is a starting point to go further in considering the function of conversational irony and the variety of effects it can have. In particular, this declaration does not explain why people opt for sarcasm, rather than simply choosing direct face attack - impoliteness and rudeness.

\section{The irony principle: mock politeness}

The term sarcasm is mainly used by theorists to limit the denotation of the term irony, which can be broadly encountered in many contexts. Irony generally refers to non-verbal phenomena. In literary studies, irony is referred to as a rhetorical device or a figure of speech. Some writers as John Dos Passos used the conversational function of irony as a linguistic technique by which two or more contrasting meanings challenge one another.

What is the conversational function of irony? To tighten up the definition we need to state the Irony Principle suggested by Leech. In order to be ironic, the speaker expresses or implies a meaning that associates a favorable value with what pertains to other persons, mainly the addressee, or associates an unfavorable value with what pertains to the speaker. At the same time, by means of the first meaning and the context, the speaker more indirectly implies a second, deeper meaning that cancels out Meaning I by associating an unfavorable value with what pertains to the other person, or associating a favorable meaning with what pertains to the speaker. The derivation of Meaning II from Meaning I is by means of two paths of inference: first, Meaning I is infelicitous (i.e., pragmatically untenable in context, often because of violation of the Cooperative Principle) and therefore to be rejected; and second, given that the meaning is infelicitous and in accordance with the Politeness Principle, the obvious way to make sense of it is to look for a related interpretation that is felicitous and not in accordance with the Politeness Principle - which is what the Irony Principle provides. The Irony Principle is a second-order principle because it is impossible to understand a remark to be ironic unless we understand it as superficially observing the Politeness Principle (Leech, 2014, p. 233).

The Irony Principle apparently involves an explanation of polite utterances appearing as impolite arguing that polite interpretations are unsustainable. In addition, the ironic interpretations may be supported by the notion of pragmaticalization. Grice's (1975) example: "You're a fine friend" (p. 53), may have both polite and ironic interpretations. As an ironic interpretation the 
utterance may be considered as a violation of Quality Maxim implicating that the hearer might be the opposite of friendly. Leech suggests a change of word order in Grice's example to: "A fine friend YOU are"; specializing in an ironic interpretation as an example of pragmaticalization (Leech, 2014, p. 234). The positioning of the intonational stress on YOU reinforces the ironic interpretation of the utterance.

It is worth mentioning that sarcastic utterances may also provide infelicity of the apparent meaning emerging from intentional exaggeration which in literary studies is ascribed as the rhetorical device of hyperbole. Now, hyperbole is apparently a breach of Quality Maxim in the sense that it indicates an overstatement of the truth. To support the theory let us consider some examples of the usage of hyperbole retrieved from John Dos Passos's Depression-era novel "1919" to implicate the mock politeness that appears as a sarcastic utterance:

(1) SPECIAL GRAND JURY ASKED TO INDICT BOLSHEVISTS (Passos, 1932, p. 248).

The deliberate exaggeration in the example appears as an infelicity condition of the apparent meaning of the utterance and a breach of Quality Maxim, as overstatement of the historical truth exposes the sarcastic intention of the utterance to express mock politeness. Another expression of an overstatement appears in the following example:

(2) The cavalree artileree

And the goddamned engineers

Will never beat the infantree

In eleven thousand years (Passos, 1932, p. 17)

Passos's sarcastic overstatement about the "unbeatable" infantry is an apparent breach of Quality Maxim as well as a violation of politeness principles. The expression "eleven thousand years" is an infelicitous statement considering the context that it appears in. In another example Passos uses an overstatement such as "eighty year old boy" referring to the historical unjust conditions:

(3) EIGHTYEAROLD BOY SHOT BY LAD WITH RIFLE (Passos, 1932, p. 90). 
All these examples are utterances with apparent infelicitous meanings being used as deliberate exaggerations by the author and convey an impolite implication as though appearing polite.

The Irony Principle presupposes two triggers for conversational irony: understatement and attitude clash (Leech, 2014, p. 237). Conversational irony was previously characterized in the paper as polite interpretation appearing untenable in context - basically because of its apparent breach of the Politeness Principle, and the contradiction between what is uttered and the attitude of the speaker no matter whether expressed through tone of voice, intonation, or other nonverbal signals. As a whole, these can be considered as "triggers" of the ironic interpretation. In Grice's terms, understatement occurs when the speaker makes obviously inappropriate claims providing less information than needed to describe some phenomena (Grice, 1975, p. 53). This apparently is a breach of the Quantity Maxim where people try to be as informative as they possibly can, and give as much information as is required, and no more. In another example from Passos's "1919" we see how the sarcastic usage of understatement breaches the maxim of Quantity:

(4) WAR DECREASES MARRIAGES AND BIRTHS (Passos, 1932, p. 91).

The second trigger for ironic interpretation of the utterance is the attitude clash. Culpeper introduces the attitude clash as a case where the apparent polite meaning and the impolite meaning of conversational irony appear alongside in the same utterance (Culpeper, 2011, p. 174). For instance, in the utterance thanks for nothing the polite expression thanks meet the attitude clash of the impolite criticism nothing. The sarcastic interpretation of the utterance breaches the politeness principles involving both polite and impolite implicatures. The attitude clash does not fully comply with the essence of conversational irony as the polite and impolite meanings both appear overt in the context. However, it is significant to mention that the sarcastic interpretation emerges from the impolite part of the utterance, like in the following example where Passos demonstrates two opposite attitudes towards the same issue:

(5) Oh the oak the ash and the weeping willow tree And green grows the grass in North Amerikee (Passos, 1932, p. 28). 
In the first line the elements "the oak", "the ash", "the weeping willow tree" convey a negative interpretation of the utterance and do not positively correlate with the expression represented in the second line - "green grows the grass", which apparently exposes the implied sarcastic meaning.

Conversational irony is inclined to be more complex, creative, witty and entertaining than a direct application of impoliteness. Sarcasm appears at different levels of delicacy and seriousness. It generally has its target but it should not be confused with direct face-attack. It primarily demonstrates a controlling behavior by the speaker. The sarcastic utterances can be considered as implicit threats but are relativity innocent in their undisguised meaning. Sarcasm works in favor of the speaker both offensively and defensively. Offensively, it achieves its impolite goal towards other people, in a way that can be interpreted as face-depriving both by the hearer and by other people present. Defensively, it means the speaker cannot easily be accused of causing offense. As a matter of fact the speaker can always claim or imply that the undisguised "innocent" interpretation is intended.

\section{Conclusion}

Summing up the outcomes of the current research it becomes apparent that sarcasm is a manifest breach of politeness as a pragmatic category. The analysis of Politeness Principle suggested by Leech provides insights on the exploitations of politeness considering sarcasm or conversational irony as one of them. It has been revealed that in sarcastic utterances the illocutionary goal opposes the social goal thus providing a breach in the model of politeness and can be viewed as negative politeness. This kind of politeness involves a negative purpose and is intended to avoid a direct offense or verbal aggression.

As a category of impoliteness, sarcasm or mock politeness is performed with the use of politeness strategies that are obviously insincere, and thus remain surface realizations. Leech's Irony Principle exposes the conversational function of irony considering polite utterances as impolite and arguing that polite interpretations are unsustainable. Ironic interpretations of utterances imply breaches of the Quality Maxim, provided by the infelicity condition of overstatement of truth, and the Quantity Maxim by understatement and attitude clash. Being an apparent breach of politeness, sarcasm or conversational irony tends to be more complex, creative, witty and entertaining than a direct application of impoliteness appearing on different levels of delicacy and seriousness. 


\section{References}

Brown, P., \& Levinson S. C. (1978). Universals in language usage: Politeness phenomena. In E.N. Goody (Ed.) Questions and politeness. (pp.56-311). Cambridge: Cambridge University Press. Retrieved from: https://www.academia.edu/26395652/Politeness_Some_universals_in_language_usage

Culpeper, J. (1996). Towards an anatomy of impoliteness. Journal of Pragmatics, 25(3), 349-367. Retrieved from: https://doi.org/10.1016/0378-2166(95)00014-3

Culpeper, J. (2011). Impoliteness: Using language to cause offence. Cambridge: Cambridge University Press.

Gibbs, R., \& Colston, L. (2007). Irony in language and thought. New York: Taylor \& Francis Group.

Grice, H. P. (1975). Logic and conversation. New York: Academic Press

Gu, Y. (1990). Politeness phenomena in modern Chinese. Journal of Pragmatics, 14 (2), 237-257. Retrieved from: https://doi.org/10.1016/0378-2166(90)90082-O

Ide, S. (1993). Preface: the search for integrated universals of linguistic politeness. Multilingua, 12 (1), 7-11. Retrieved from: http://www.sachikoide.com/1993_Preface_The_Search_for_Integrated_Universals.PDF

Leech, G. (1983). Principles of pragmatics. London: Longman.

Leech, G. (2014). The Pragmatics of politeness. New York: Oxford University Press.

Mao, L. M. (1994). Beyond politeness theory: "Face" revisited and renewed. Journal of Pragmatics, 21, 451-486. Retrieved from: https://www.academia.edu/5436544/Beyond_politeness_theory_Face_rev isited_and_renewed

Matsumoto, Y. (1988). Reexamination of the universality of face: Politeness phenomena in Japanese. Journal of Pragmatics, 12, 403-426. Retrieved from: http://dx.doi.org/10.1016/0378-2166(88)90003-3

Wierzbicka, A. (1991/2003). Cross-cultural pragmatics: The semantics of human interaction. Berlin: Mouton de Gruyter.

\section{Sources of Data}

Passos, J. D. (1932). Nineteen Nineteen. New York: Harcourt, Brace and Co. 


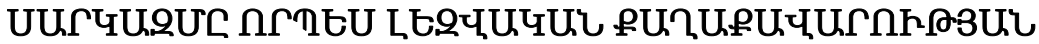

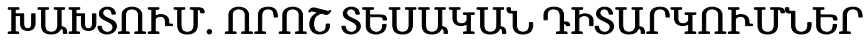

\section{Zujl Tuquhtjuwi}

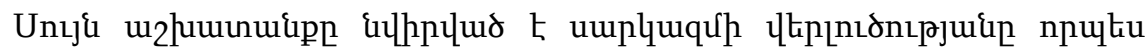

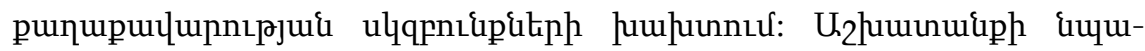

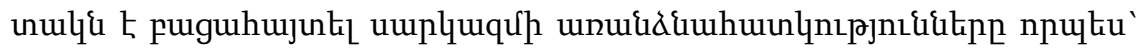

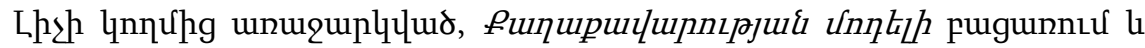

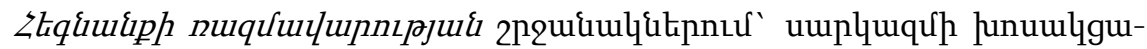

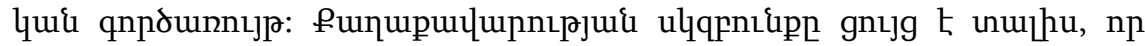

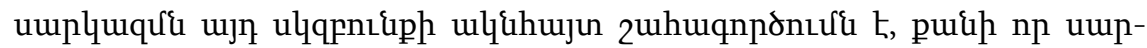

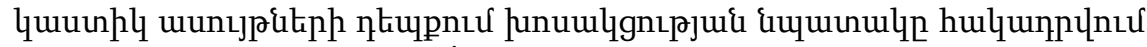

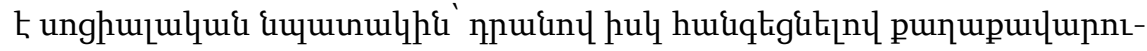

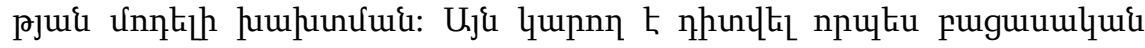

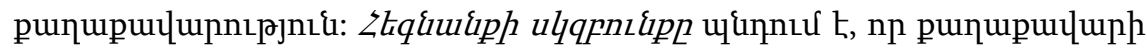

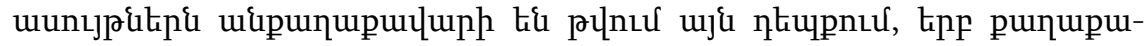

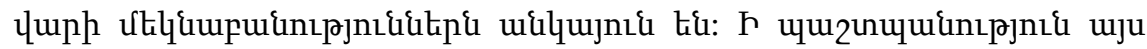

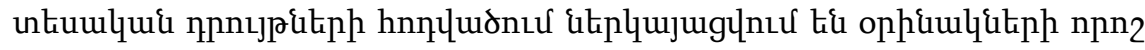

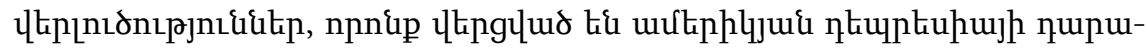

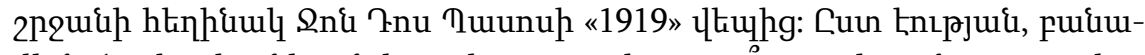

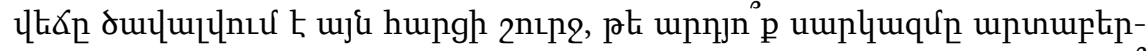

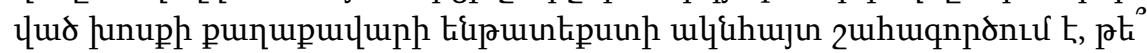

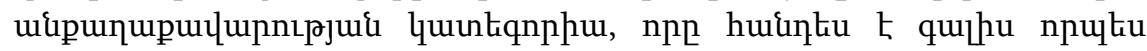
punupul|upnıрјuif dunpuiqp:

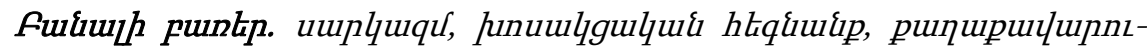

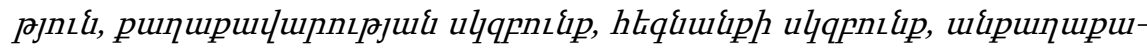

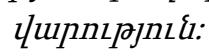

